\title{
Os Donos da História e o Autor de Os Donos do Poder
}

\author{
Nanci Leonzo \\ Departamento de História - FFLCH/USP
}

\begin{abstract}
O falccido Collingwood gostava de dizer que o tipo de história que alguém cscrevia, ou o modo como rcflctia sobrc a História, cra em última análise uma funçāo do tipo de homem que sc cra. Mas o inverso também é verdadciro.
\end{abstract}

WHITE, 1992 , p. 440

Os historiadores brasileiros têm um grande mérito: jamais se reuniram para discutir se este ou aquele intelectual deve ou não ingressar na nossa corporaçāo. Pelo menos neste aspecto nos distanciamos dos franceses, os quais, no final dos anos $70, \mathrm{em}$ reunião promovida pela revista Magazine Litteraire, ousaram colocar a prêmio a cabeça de Michel Foucault. Vale recordar o episódio, no qual prevaleceu, felizmente, o bom senso de Paul Veyne. Revelou este colóquio, do qual participaram Phillippe Ariès, Emmanuel Le Roy Ladurie, Jacques Le Goff c Michel de Certeau, que não havia um consenso sobre a investida interdisciplinar de Foucault. Certeau, por exemplo, chegou a afirmar que o autor de História da Loucura na Idade Clássica não ocupava a "posição e a funçāo" de historiador; era apenas um "filósofo da historiografia" (LE GOFF, 1978, pp. 36-46). Ao que tudo indica, a vítima jamais deu ouvidos aos seus inquisidores, ignorando todos os tribunais destinados a questionar suas legítimas incursōes pela História. Faço questāo de registrar o incidente para que sirva de exemplo do que nunca deveremos imitar, nós que já tanto imitamos.

No Brasil, como ć sabido, é considerável o número de "obras históricas" assinadas por pessoas que nāo possuem, na gaveta, um diploma de bacharel em História. Jamais as colocamos na berlinda, mas mantemos, com algumas delas, uma relação curiosa, na qual se mesclam respeito e indiferença. Os exemplos são muitos, mas fico com Raymundo Faoro, o conceituado jurista que há quase quatro décadas insiste na busca de respostas para os grandes dilemas brasileiros.

Carlos Guilherme Mota talvez tenha sido o único historiador a registrar a importância, no cenário cultural brasileiro, do lançamento, em 1958, de Os Donos do Poder: Formaçāo do Patronato Político Brasileiro. Considero sua curta - mas instigante - análise deste clássico um ponto de referência obrigatório para toda e qualquer análise historiográfica que re- 
pouse sobre os anos 50. Segundo Mota, Os Donos do Poder é um livro "de inspiração weberiana" (MOTA, 1977, pp. 178-181). A afirmação é correta, mas exige uma complementação, pois no prefácio à $2^{0}$ edição, isto é, em 1973, assim se expressou Faoro:

Advirta-se que este livro nāo sugere, apesar de seu próximo parentesco, a linha de pensamento de Max Weber. Năo raro, as sugestōes weberianas seguem outro numo, com novo conteúdo e diverso colorido. De outro lado, o ensaio se afasta do marxismo ortodoxo, sobretudo ao sustentar a autonomia de uma camada de poder, não diluída numa infra-estrutura esquemática que daria conteúdo econômico a fatores de outra índole (FAORO, 1975, vol. I, p. XIII).

Sem abandonar Weber, Raymundo Faoro atestava, publicamente, seu envolvimento com o marxismo. O italiano Gramsci será, nos próximos anos, uma de suas leituras prediletas. Mas antes de divulgar suas preferências teóricas, as quais tornariam seus textos ainda menos digestivos para boa parte dos docentes universitários, Faoro enveredou pela literatura. Des. ta vez o arcabouço weberiano ganhou um "colorido" especial. É flagrante a influência de Lucien Goldman na concepção formal de A Pirâmide e o Trapézio, cuja $1^{\mathrm{a}}$ edição data de 1974. O forte deste livro não é, entrẹtanto, a sociologia estruturalista genética desenvolvida por Goldman em sua lúcida tentativa dc filtrar Luckacs. Mesmo porque Faoro nāo tem o hábito de importar "teorias". Na verdade, o que se destaca em A Pirâmide e o Trapézio é uma interpretaçāo da estrutura social do Segundo Reinado, já esboçada em Os Donos do Poder, e delineada com base no pressuposto de que houve no Brasil, durante a segunda metade do século XIX, uma gradativa substituiçāo da velha sociedade de estamentos pela sociedade de classes (FAORO, 1988). O que se observa, em linhas gerais, é a análise política suplantando a literária; é Joaquim Nabuco explicando Machado de Assis.

Um nome estará sempre ligado ao de Raymundo Faoro: Joaquim Nabuco, autor de Um Estadista do
Império, obra que, provavclmente, Faoro jamais se cansará de reverenciar ${ }^{1}$. Nela a política imperial teria sido retratada por um adepto da "história artística", interessado cm "alcançar o processo histórico com o fino trabalho do escultor e pintor, cavalgando o documento frio, mas indócil ao artista". Essa prática o fascina, mais ainda, o estimula, na medida $\mathrm{cm}$ que reserva um espaço para a criação. Ele, como Nabuco, parece desejar ser o escultor, o pintor, como testemunha o cnsaio "A Ponte Suspensa", o tercciro e último de seu mais recente livro lançado com um provocativo título: Existe um Pensamento Político Brasileiro?

Agora, provavelmente, Raymundo Faoro terá que fornecer poucas justificativas sobre o seu apego a Max Weber, já que o primeiro ensaio deste seu último livro é precedido de uma reflexăo de forte inspiraçāo gramsciana:

O pensamento político de cada um nāo se afirma na forma intelectual, mas na atividade real implicita na açāo, ainda que, à margem desta, afirme-se outra idéia. A eventual contradiçāo entre a regra e a conduta rompe-se privilegiando a conduta: ncla está o pensamento político real, embora a contradição intelectual nada tenha a ver com a má fé (FAORO, 1994, p. 16).

Trata-se de uma fé de ofício perpassando por um texto cujo aparato conceitual atua como fio condutor dos três ensaios. Raymundo Faoro assume a identidade de cientista político num país onde contam-se nos dedos aqueles que analisam a ação política sem apelar para abstraçōes pulverizadas de retórica. Isto The garante o direito de levantar os fatores explicativos de nossa realidade, de elaborar sínteses, de construir uma "história artística". Isto também o legitima ainda mais perante a desconfiada comunidade de historiadores.

1. A $1^{0}$ edição de Um Estadista do Império. Nabuco de Araujo. Sua Vida. Sua Opinião, Sua Época vejo à luz em 1896. 
É preciso ir mais longe, admitindo que ele esteve sempre na vanguarda, lendo Weber e Marx quando somente se lia Marx, recorrendo a Gramsci quando somente se recorria a Althusser. Mas, por ter optado por uma trilha deserta, ainda que segura, permaneceu à margem dos viciados caminhos que levaram às salas de aula boa parte dos estudiosos brasileiros que despontaram nas décadas de 50 e 60 . Muitos destes, como Faoro, não dispunham de um diploma de bacharel em História, porém, tinham uma característica comum, qual seja, contestavam abertamente o status quo. Eram vistos como "esquerdistas", o que a muitos bastava. Ao longo dos anos, Raymundo Faoro parece ter aprendido a conviver como os pretensos donos do poder acadêmico, que insistiam em não reconhecer sua contribuição para a autonomia de nossa história política. Contiṇưư a trabalhar ern silêncio, nas horas vagas. Nos anòs 70 , quando chegou à grande imprensa por estar à frente do Conselho $\mathrm{Fe}$ deral da Ordem dos Advogados do Brasil, passou a ser visto com outros olhos.

Sua incansável militância em prol das liberdades democráticas, entretanto, não se mostrou suficiente para que os exemplares de Os Donos do Poder fossem disputados entre os alunos dos cursos de História. Vencida a rejeição ideológica, restou um inimigo maior: o despreparo teórico dos que ganham a vida ensinando História do Brasil. Contra este mal, há pouco o que fazer. Não é fácil lutar contra as facilidades didáticas obtidas com a simples importaçāo de objetos, abordagens e problemas. Observe-se, por exemplo, o que ocorre, na atualidade, no âmbito da história política. Tāo logo os franceses decidiram "renová-la", procuramos copiá-los, trazendo o debate para as universidades e revistas especializadas, com o objetivo, é claro, de mostrar a necessidade de também "renovar" a nossạ hiistória política. Ocorre, todavia, que desconhecemos a nossa produção nesta área do conhecimento. Nāo dispomos de avaliações quantitativas e, principalmente, qualitativas. Então, como pensar em "renovar" o ignorado?

Sustento a hipótese de que sempre produzimos uma história política de boa qualidade. Vou além. Raymundo Faoro teve um papel decisivo na busca dessa qualidade. Assim, penso ser oportuno ressaltar uma problemática contemporânea que talvez desperte um novo interesse pela leitura de suas obras. É a que diz respeito à "história artística". Dela Faoro se revela um fervoroso adepto:

Risco inerente às objetividades possíveis e várias, o das visōes múltiplas, que assume quem, historiador ou romancista, se liberta das convenções artificiais. A lâmpada, que deforma a imagem no espelho, arde em todos os altares. Negá-la seria esconder os pressupostos das ciências sociais. Esforço inútil e estéril de escamoteamento, falsa arte que esfalfou os positivistas e naturalistas, nem só do século passado, senão os de agora, montados em outros dogmatismos (FAORO, 1988, pp. 480-481).

As palavras são do início dos anos 70 , mas nunca perderam sua validade para Faoro, ainda que em seus textos essas visões múltiplas tendam a submergir num mar de metáforas. A lâmpada que arde em seu altar nunca se apaga, pois tem o dever de iluminar a construçāo de um discurso envolvente, que o resguarda de um desmentido e the garante um lugar de honra na cultura brasileira. Cabe aqui uma advertência. Se o leitor chegar, por exemplo, à conclusāo de que ela deforma, em a "Ponte Suspensa", a imagem de nossa política imperial, convém esquecer. Nāo vale a pena quebrar o espelho. Para bem compreender Raymundo Faoro é preciso desistir de chegar à ciência através da ciência. $O$ caminho é a arte. Burckhardt e Huizinga talvez sejam um bom começo. Weber e Gramsci podem esperar. 


\section{Bibliografia}

FAORO, Raymundo. Existe um Pcnsamento Politico Brasileiro? São Paulo, Ática, 1994.

. Machado de Assis: A Pirámide c o Trapczio. 3. ed. Rio de Janeiro, Globo, 1988.

Os Donos dio Poder. Formação do Patronato

Polttico Brasileiro. 2' ed. Rio de Janeiro, Globo; Sāo

Paulo, Edusp, 1975, vul. i.
LE GOFF, Jacques e outros. A Nova História. Lisboa, Ediçōes 70, 1978.

MOTA, Carlos Guilherme. Ideologio da Cultura Brasilcira (1933-1974). São Paulo, Ática, 1977.

WHITE, Hayden. Mcta-Historia. A Imaginaçáo Histórica do Sćculo XIX. Sâo Paulo, Edusp, 1992.

Endereço da Autora: Faculdade de Filosofia, Letras e Ciências Humanas/USP - Departamento de História - Avenida Professor Lincu Prestes, 338 - CEP 05508-900 - Cidade Universitária - Sāo Paulo-SP - Brasil - FAX 818-3750 